\title{
Extracranial Internal Carotid Artery Aneurysms: Case Report of a Saccular Wide-Necked Aneurysm and Review of the Literature
}

\author{
A. K. Al Miraj ${ }^{1 *}$, Md. Saleh Ahammed ${ }^{2}$, Mohammad Ata Ullah ${ }^{3}$, Muhammad Abduz Zaher ${ }^{4}$, A. K. M. Latiful Bari ${ }^{5}$,
} Shohel Mahmud Khan ${ }^{6}$, Md. Kawsur Ahmed ${ }^{7}$, Md. Wares Ali ${ }^{8}$, Md. Magfur Rahman ${ }^{9}$

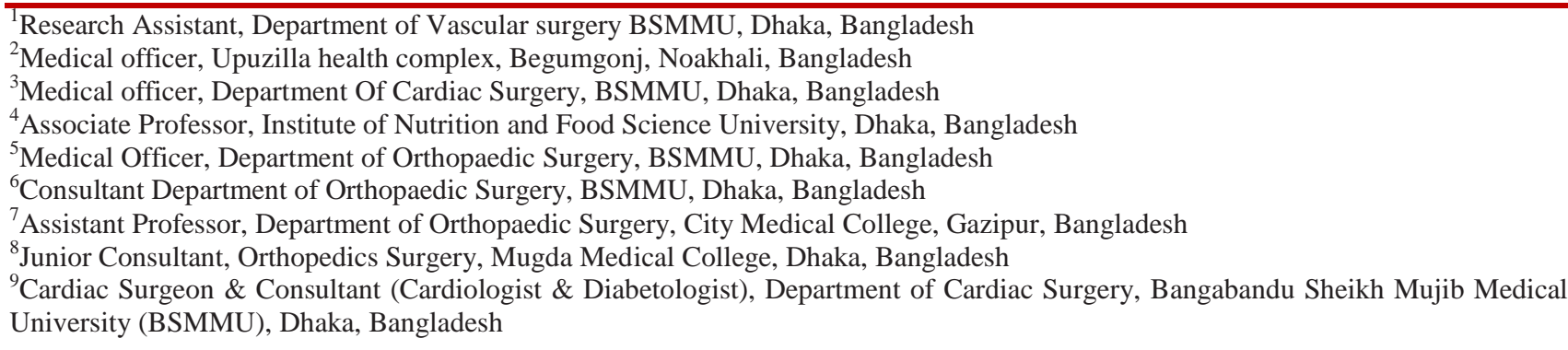

DOI: $\underline{10.36347 / \text { sjams.2021.v09i02.019 }}$

| Received: 09.02.2021 | Accepted: 22.02.2021 | Published: 27.02.2021

*Corresponding author: A. K. Al Miraj

Abstract

\begin{abstract}
Purpose to describe a case of atherosclerotic Extracranial internal Carotid Artery Aneurysm (EICAA) with an unique "Oval" morphological structure, surgically treated and to review the ex-periences of major referral centers. Case Report: a 60-year-old woman presented with a slowly growing pulsatiling mass for 2 and $1 / 2$ years years, Occ. dysphagia and Occ. Headeche and Digginess; duplex ultrasonography and MRA scan demonstrated a wide-necked, saccular aneurysm at the origin of the right Internal Carotid Artery (ICA). A total aneurysmectomy with end to end to end anastomosis of the aneurysm of the neck on the carotid wall was successfully performed. No perioperative complications were encountered; at two months follow-up the patient was symptoms significantly subsided without any neurological complication and with carotid patency about 45-50\% stenosis. Conclusions: open surgery remains may be the gold standard for the treatment of extracranial internal carotid artery aneurysms in terms of patency and reduced risk of adverse complications; endovascular procedures may, in selected cases, provide a valuable additional tool in the armoury of the physician. (www.bsmmu.org.bd).

Keywords: Extracranial carotid artery, carotid aneurysm, surgery.

Copyright $\odot 2021$ The Author(s): This is an open-access article distributed under the terms of the Creative Commons Attribution 4.0 International License (CC BY-NC 4.0) which permits unrestricted use, distribution, and reproduction in any medium for non-commercial use provided the original author and source are credited.
\end{abstract}

\section{INTRODUCTION}

Extracranial internal Carotid Artery (ECA) Aneurysms are a rare entity, estimated at $0.1 \%$ to $2 \%$ of all carotid procedures performed at major referral centers (One in BSMMU from 2004 to 2013). They can be classified according to their different physiopathology into true or false aneurysms and according to their etiology into atherosclerotic, dysplastic, infective, posttraumatic and iatrogenic [1,2]. ECA Aneurysms may be asymptomatic but neurologic manifestations are the most frequent symptoms [3, 4]. The natural history of this pathology is associated with spontaneous progression of the aneurysm, most commonly associated with a high risk of neuro- logical thromboembolic events, cranial nerve com- pression and, more rarely, rupture [5]. The surgical treatment of
ECA aneurysms is determined by the aetiology, size and locationof the aneurysm and any associated contraindications. Whereas antiplatelet and anticoagulant drugs are considered by many authors as the first-line approach for asymptomatic aneurysmal lesion, open surgery still remains the most valid option to prevent the most probable, severe and life-threatening complications, in particular embolisms [1]. Endovascular treatment, especially in the light of the recent progress in stent grafting, may be considered as a therapeutic choice but only in selected cases; more comparative studies and long-term follow up will be necessary to assess the role of endoluminal exclusion as a first choice treatment.

\section{CaSe REPORT}


A. K. Al Miraj et al; Sch J App Med Sci, Feb, 2021; 9(2): 271-276

A 60-year-old woman was admitted to our Vascular Surgery ward with a diagnosis of Extracranial internal Carotid Artery aneurysm. The patient presented with a large, growing, pulsatile mass in the right side of the neck (easily palpated due to the slimness of the patient's neck). Auscultation evidenced no pathological carotid bruit. Her reported persistent symptoms of dysphagia, and transient hypophonia; there was no history of cerebrovascular symptoms or cervical trauma. The patient reported a medical history significant for hyperlipidemia with drug-controlled familiar hypercolesterolemia; there was no familiarity for chronic arteriopathy. The diagnosis was established through duplex ultrasonography followed by a cerebral and neck com- puted tomography: angio-CT scan revealed a wide- necked, saccular, "diverticulum-like" aneurysm at the origin of the right ICA, developing from the side of the carotid wall with a diverticular shape, with a lon- gitudinal diameter of $15 \mathrm{~mm}$ and transversal diameters of $14 \mathrm{~mm} \times 13 \mathrm{~mm}$ (Fig $1 \& 2$ ); in addition, a small atherosclerotic, calcific plaque of the bulbar ICA without hemodynamic flow impairment was shown; the left carotid axis appeared free from aneurysmatic lesions with an atherosclerotic, nonstenotic plaque at the carotid bifurcation. No other aneurysms were identified in the cerebral circulation. Further preoperative angiographic investigation was deemed unnecessary.

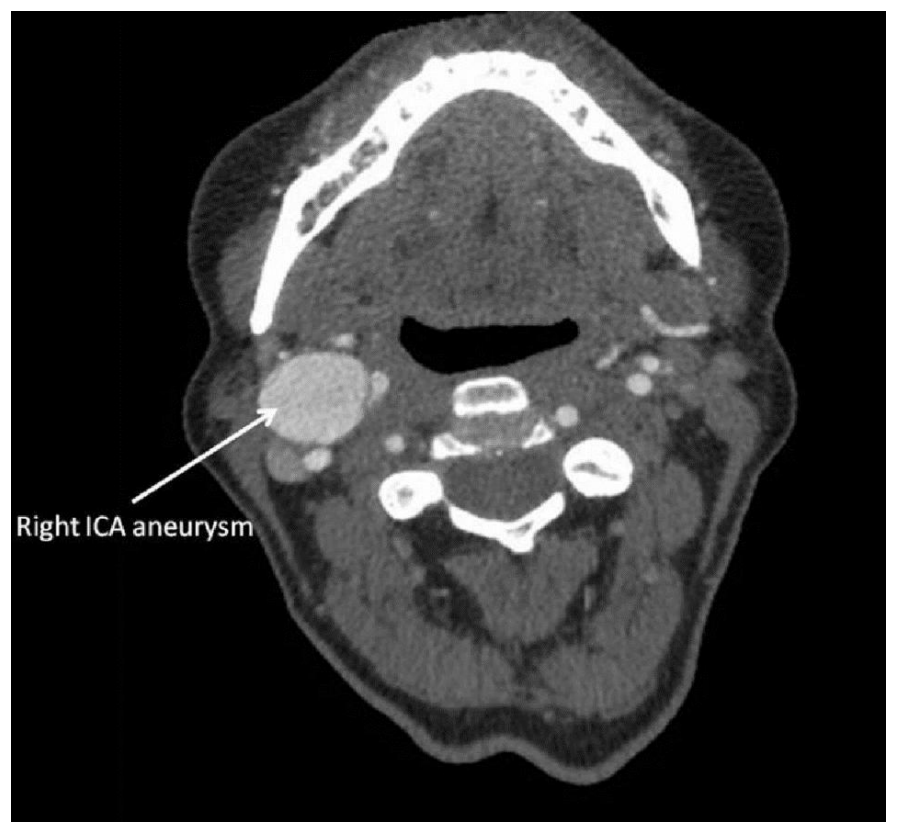

Fig-1: Angio-CT Scan: lateral view of the right carotid axis

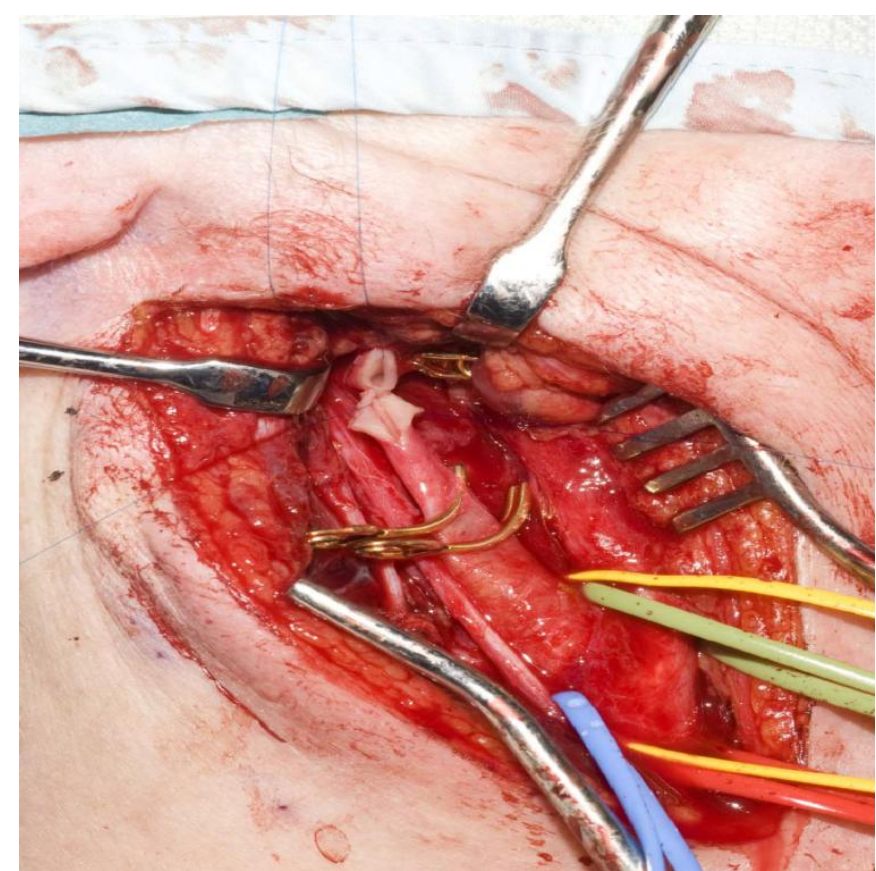

Fig-2: Angio-CT Scan: frontal view of carotid axis 


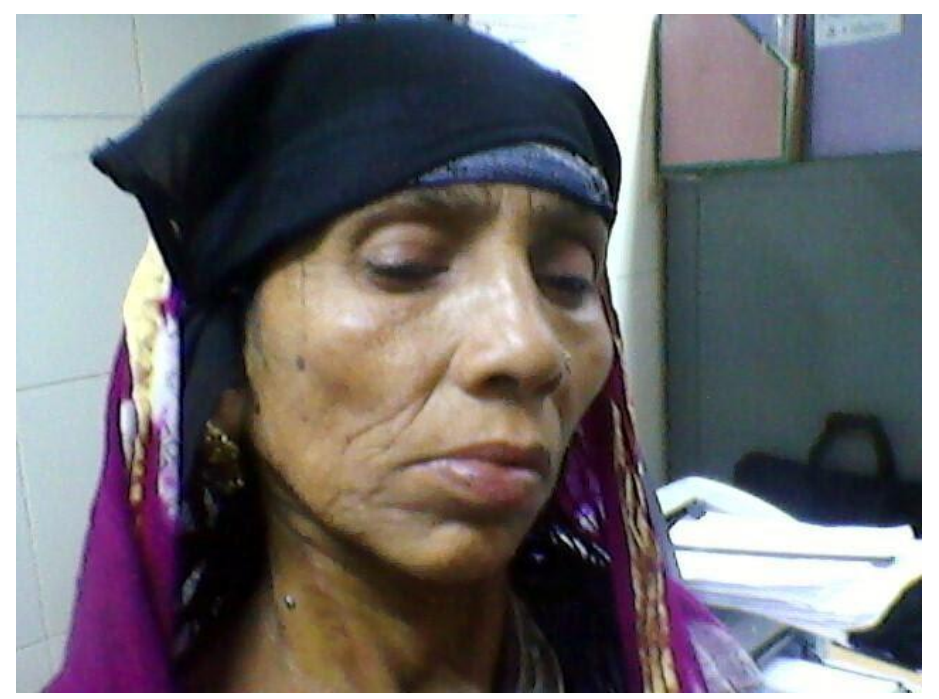

Fig-3: Intraoperative view: wide-necked, saccular, "diverti- culum like" aneurysm at the origin of the right ICA

The ECA aneurysm was surgically treated under loco-regional anesthesia; the carotid branches and the aneurysm were exposed using a short standard lateral cervical incision obtaining limited isolation and control of the cervical carotid aneyrysm (CCA), ECA, and proximal and distal ICA (Fig-3). Intraluminal shunting was unnecessary as no neurological symptoms presented after carotid clamping. Due to the unusual saccular, wide necked, "diverticulum like" shape of the aneurysm, we performed an Extracranial Internal Carotid Artery Aneurysms aneurysmectomy with Dacron-patch closure of the re- maining carotid wall, preserving the lumen of the native artery, thereby reducing the risk of injury to the vagal, recurrent laryngeal and glossopharyngeal cranial nerves (Fig 4 \& 5). No adverse neurological events (focal or non-focal) were intra or perioperatively observed; pathologic examination of the aneurysmatic carotid wall revealed severe complicated atherosclerotic lesions. The patient was hospitalised for 4 days and dis- charged with antiplatelet therapy. One month, 6 months and 1 year Duplex Scan follow-ups were performed which showed patency of the carotid axis with regular blood flow. The patient appeared asymptomatic.

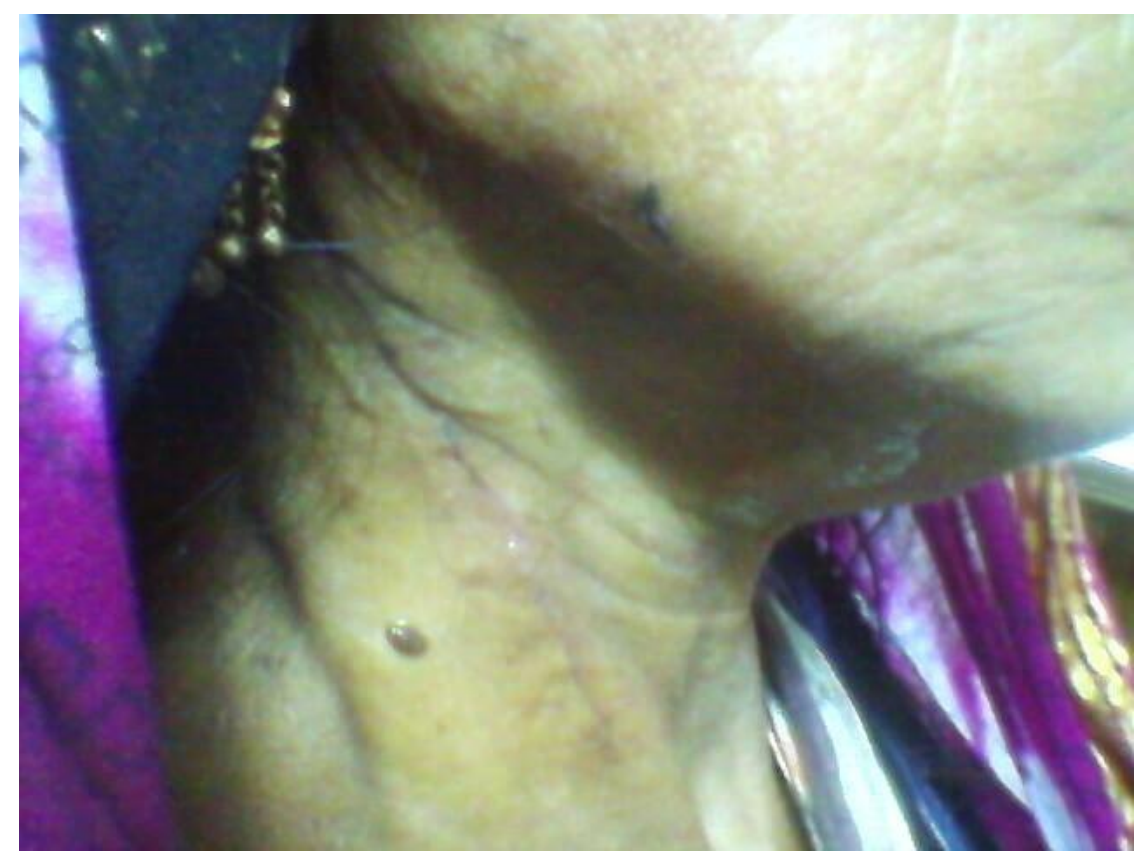

Fig-4: Intraoperative view: aneurismectomy with Dacron- patch closure 


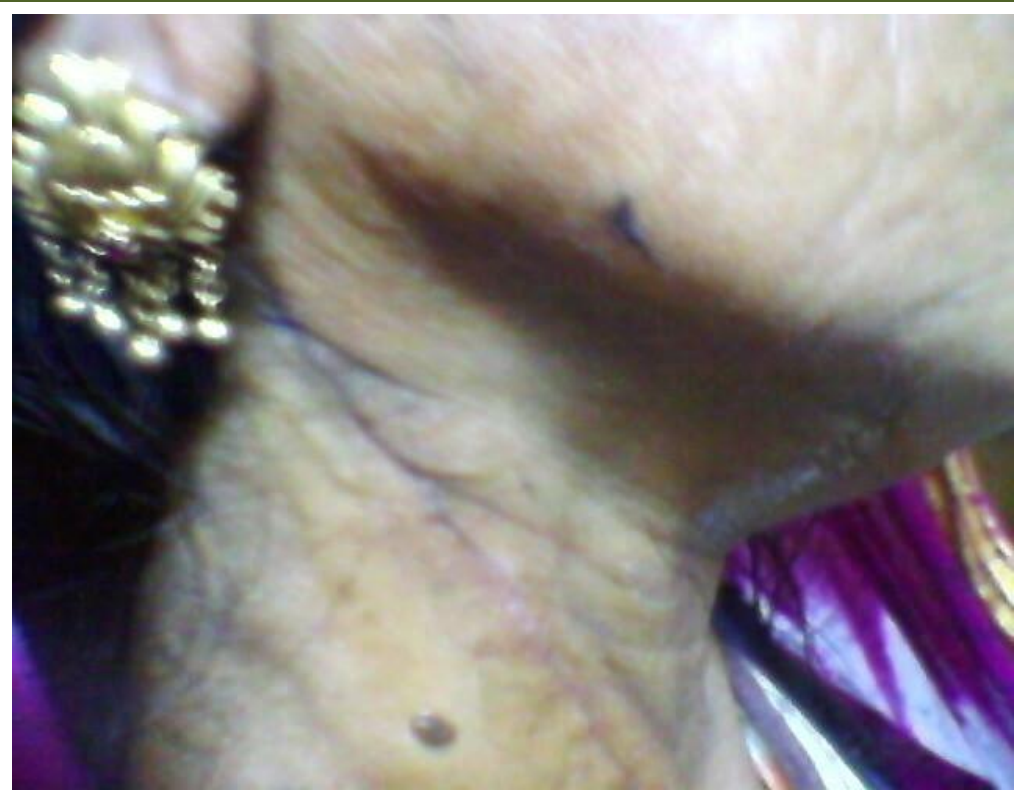

Fig-5: Intraoperative view: final result

\section{DisCUSSION}

Extracranial internal Carotid Artery aneurysms are defined as localised increases of the calibre of more than $50 \%$ as compared with the reference values of the ICA $(0.55 \pm 0.06 \mathrm{~cm}$ in men; $0.49 \pm 0.07$ in women $)$. They are a rare entity: 853 cases were retrospectively reviewed by Schechter from 1687 to 1977 [6]. The largest, to date, single center study was carried out by the Texas Heart Institute (THI) between 1960-1995 with 67 cases. They may be classified like true or pseudo-aneurysms according to their different aetiologies. Pseudoaneurysms (PAs) comprise only $14 \%$ of ECA aneurysms in the reviewed literarature [7] even though they exceptionally represented the $57 \%$ of these causes in the THI series (El Sabrout et al., [1]. PAs are mainly secondary to previous endoarterectomy (CEA) with the onset of symptoms ranging from 1 month to 15 years after the original carotid procedure; other contributing factors of PAs may be trauma (car accidents, stab-wounds, iatrogenic central venous cannulation) and infections: patch complications or recurrent tonsillitis or pharingitis reaching the carotid artery wall following peritonsillar abscess with subsequent ischemia of the wall leading to acute rupture or causing septicemia and invasion of vasa vasorum [8]. The usual infectious agents are staphylococcus aureus and streptococcus pyogenes. This etiology was firstly described in 1843 by Liston [9]. In 1933 Salinger and Pearlman reviewed 228 cases [10]. Before the introduction of antibiotics, infection was the main cause of ECA aneurysms but since then, only 31 ad-ditional cases have been reported $[11,12]$. True aneurysms are most commonly due to atherosclerosis or fibromuscolar dysplasia. Although Moreou reported dysplastic lesions (single or associated with spontaneous dissection) as a major cause of ICA aneurysms [13], atherosclerotic degeneration is assumed to be the most frequent etiology $[14,15]$ : up to $53 \%$ in a review of the literature by McCann ('72-'85) [2]. Atherosclerotic Aneurysms (AAs) are usually found in patients aged 50 to 70 years old with a male- female ratio of 1.9:1 [16]. AAs may involve various portions of the carotid artery: they tend to be located in the common artery bifurcation and in the proximal ICA, size ranging from 1.5 to 5.0 $\mathrm{cm}$, whereas dysplastic aneurysms, of- ten associated with chronic dissection are more distally located [17]. Carotid aneurysms of the external carotid artery are less frequent but should also be considered in the differential diagnosis of patients presenting with a pulsating mass in this area. Traumatic aneurysms are either due to compres- sion and stretching of the artery on the lateral mass of the 1st cervical vertebra or the shearing of the artery at the level of its intracranial entry $[18,19]$. Other rare contributing factors to aneurysm for- mation include neck irradiation, neurofibromatosis, Marfan's Syndrome, Bechet's Syndrome and Takayasus's arteritis [20]; $30 \%$ to $60 \%$ of ECA aneurysms are symptomatic for thromboembolic focal or non-focal symptoms; more rarely cranial nerve compression may result in neurological deficits (as shown in our patients clinical presentation). Spontaneous progression of ECA aneurysms is associated with a higher risk of mainly thromboembolic neurological complications; other adverse events may be rupture, with massive haemorrhage, and nerve compression [3]. Conservative treatment is based on anticoagulant or antiaggregant therapy. A non-surgical approach may be indicated in young patients with asympto- matic, traumatic or spontaneous dissecting aneurysms [1]. In many cases, however, medical treatment is considered to be ineffective or even dangerous, with a persistent risk of damage due to haemorrhage [21]. Before $1950,71 \%$ of the patients non-surgically treated later died because of complications due to the aneurysm [22]. More recently one-fifth of ECA aneurysms were non-surgically managed with an overall stroke rate of $50 \%$ [23]. Surgical treatment of ECA aneurysms may 
A. K. Al Miraj et al; Sch J App Med Sci, Feb, 2021; 9(2): 271-276

therefore be seen as a first-line approach, even in asymptomatic patients. The main indication for a surgical approach is the prevention of permanent neurological deficits arising as sequelae of thromboembolism. Historically, the first successful operation was performed by Sir Astley Cooper in London, in 1808: the patient was a 50-year-old labourer with a bulbar aneurysm of the ICA that was "about the size of a pullets egg" with a "remarkably strong pulsation of the tumour [24]. Until the 1950s surgical treatment of ECA aneurysms only consisted of carotid ligation, with an alarming mortality / major stroke rate of $20 \%$ to $60 \%$ (nowadays ligation is only performed in about $10 \%$ of the cases, mainly if a distal ICA plaque occlusion is present) [25]. By the 1970s, reconstruction of the carotid axis had definitely replaced ligation as a treatment option. The success of open surgery is dependent on the aetiology, size, and location of the aneurysm and associated comorbidities. The most frequent surgical procedures for Atherosclerotic Aneurysms are represented by: total resection of the aneurysm with direct end-to-end anastomosis or interposition of a prosthetic graft or the saphenous vein; rarely performed, it may be indicated for fusiform aneurysms; partial aneurysmorraphy and patch (synthethic or venous) closure; this may be indicated in saccular aneurysms. The aim is the preservation of the posterior carotid wall, thus reducing the risk of cranial nerve injuries; extracranial intracranial by-pass graft: this is a very difficult and rarely per-formed technique, moreover it does not exclude the aneurysm from the blood stream and therefore does not eliminate the risk of embolization or rupture unless followed by carotid ligation; in the presented case, due to the unique morphological structure of the aneurysm ("diverticulum-like"), we performed a total aneurysmectomy with patch angioplasty of the aneurysm of the neck on the carotid wall to restore the normal lumen of native artery; in our review of the literature we did not find any similar presentation justifying this surgical approach. A review of the literature suggests that surgical repair has proven to be effective and safe in the following situations: THI [1]: 67 aneurysms in 35 years with a 9\% overall mortality/major stroke incidence and a $6 \%$ rate of cranial nerve injury; Zhang [26]: 66 aneurysms in 17 years with a $1.6 \%$ immediate death rate and a $6 \%$ rate of adverse events; D'addato [14]: Extracranial Internal Carotid Artery Aneurysms 24 aneurysms in 21 years with no perioperative deaths and $4.5 \%$ immediate major or minor adverse events. This is compared with an estimated complication rate of between 20 to $71 \%$ in non-surgically treated ECA. However it should be noted that open surgery may be invasive, disabling and extremely difficult when lesions are located in the distal portion of the ICA, at the base of the skull with a high risk of cranial nerve damages (permanent nerve palsies up to $42 \%$ in Mokri et al., [16]. This may be the reason why endovascular proce- dures have been recently used in the treatment of ECA aneurysms by means of embolization with de- tachable coils, endografts or covered stents. The largest series up to date was reported by Bergeron et al., (6 cases endovascularly treated) [27]. The use of covered stenting allows simultaneous exclusion of the aneurysm and dilatation of an even- tually stenosed distal ICA, with excellent results in terms of patency and absence of migration [28]. Very few neurological complications following endovascular exclusion and little nerve damage have been reported. By contrast, it should be noted that stented seg- ments of the carotid artery have been shown to have less flexibility when the patient moves his head [29]. In addition, endoluminal treatment of distal ICA aneurysms does not offer the possibility of surgical conversion in case of complications durino or after the procedure. In conclusion, studies of larger series of patients with extensive post-operative followup will be required to prove the safety and efficacy of endovascular procedures. In this case, the presence of a wide neck (saccular, "diverticulum-like" aneurysm), suggested that the open surgery approach was the best treatment for the patient, in terms of patency and the reduced risk of adverse complications (the patient's thin neck made the task easier).

\section{Conclusion}

In conclusion, we believe that, while open surgery remains the gold standard to treat ECA aneursysms, endovascular procedures may, in the future and for selected cases, provide a valuable additional tool in the armoury of the physician.

\section{REFERENCES}

1. El-Sabrout, R., \& Cooley, D. A. (2000). Extracranial carotid artery aneurysms: Texas Heart Institute experience. Journal of vascular surgery, 31(4), 702-712.

2. McCann, R. L. (1990). Basic data related to peripheral artery aneurysms. Annals of vascular surgery, 4(4), 411-414.

3. Szopinski, P., Ciostek, P., Kielar, M., Myrcha, P., Pleban, E., \& Noszczyk, W. (2005). A series of 15 patients with extracranial carotid artery aneurysms: surgical and endovascular treatment. European journal of vascular and endovascular surgery, 29(3), 256-261.

4. Azzarone, M., Cento, M., Gobbi, S., \& Tecchio, T. (2003). Neuropathy as the only symptom of common carotid artery spontaneous rupture: Case report. Journal of Cardiovascular Surgery, 44(6), 767-769.

5. Rosset, E., Albertini, J. N., Magnan, P. E., Ede, B., Thomassin, J. M., \& Branchereau, A. (2000). Surgical treatment of extracranial internal carotid artery aneurysms. Journal of vascular surgery, 31(4), 713-723.

6. Schechter, D. C. (1979). Cervical carotid aneurysms. NY State J Med. 79: 892-901. 
A. K. Al Miraj et al; Sch J App Med Sci, Feb, 2021; 9(2): 271-276

7. Pulli, R., Gatti, M., \& Credi, G. (1997). Extracranial carotid artery aneurysms. $J$ Cardiovasc Surg, 38: 339-346.

8. Gralla, J., Brekenfeld, C., Schmidli, J., Caversaccio, M., Do, D. D., \& Schroth, G. (2004). Internal carotid artery aneurysm with lifethreatening hemorrhages in a pediatric patient: endovascular treatment options. Journal of Endovascular Therapy, 11(6), 734-738.

9. Liston, R. (1843). On a variety of false aneurysms. Br Foreign Med Rev, 15: 155-161.

10. Salinger, S., \& Pearlman, S. J. (1933). Hemorrhage from pharyngeal and peritonsillar abscesses: report of cases, resume of the literature and discussion of ligation of the carotid artery. Archives of Otolaryngology, 18(4), 464509.

11. Reisner, A., Marshall, G. S., Bryant, K., Postel, G. C., \& Eberly, S. M. (1999). Endovascular occlusion of a carotid pseudoaneurysm complicating deep neck space infection in a child: Case report. Journal of neurosurgery, 91(3), 510514.

12. Stevens, H. E. (1990). Vascular complication of neck space infection: case report and literature review. The Journal of otolaryngology, 19(3), 206210 .

13. Moreau, P., Albat, B., \& Thévenet, A. (1994). Surgical treatment of extracranial internal carotid artery aneurysm. Annals of vascular surgery, 8(5), 409-416.

14. Faggioli, G., Freyrie, A., Stella, A., Pedrini, L., Gargiulo, M., Tarantini, S., ... \& D'Addato, M. (1996). Extracranial internal carotid artery aneurysms: results of a surgical series with longterm follow-up. Journal of vascular surgery, 23(4), 587-595.

15. Welling, R. E., Taha, A., Goel, T., Cranley, J., Krause, R., Hafner, C., \& Tew, J. (1983). Extracranial carotid artery aneurysms. Surgery, 93(2), 319-323.

16. Mokri, B., Piepgras, D. G., Sundt Jr, T. M., \& Pearson, B. W. (1982, May). Extracranial internal carotid artery aneurysms. In Mayo Clinic Proceedings (Vol. 57, No. 5, pp. 310-321).

17. Valentine, R. J. (2003). Asymptomatic internal carotid artery aneurysm. Journal of vascular surgery, 37(1), 210.

18. Mokri, B. (1990). Traumatic and spontaneous extracranial internal carotid artery dissections. Journal of neurology,237(6), 356361.

19. Alimi, Y. S., Di Mauro, P., Fiacre, E., Magnan, J., \& Juhan, C. (1996). Blunt injury to the internal carotid artery at the base of the skull: six cases of venous graft restoration. Journal of vascular surgery, 24(2), 249-257.

20. Tabata, M., Kitagawa, T., Saito, T., Uozaki, H., Oshiro, H., Miyata, T., \& Shigematsu, H. (2001). Extracranial carotid aneurysm in Takayasu's arteritis. Journal of vascular surgery, 34(4), 739. 742.

21. de Jong, K. P., Zondervan, P. E., \& van Urk, H. (1989). Extracranial carotid artery aneurysms. European journal of vascular surgery, 3(6), 557-562.

22. Shipley, A. M., Winslow, N., \& Walker, W. W. (1937). Aneurysm in the cervical portion of the internal carotid artery: an analytical study of the cases recorded in the literature between august 1 , 1925, and july 31, 1936 report of two new cases. Annals of surgery, 105(5), 673-699.

23. Zwolak, R. M., Whitehouse Jr, W. M., Knake, J. E., Bernfeld, B. D., Zelenock, G. B., Cronenwett, J. L., ... \& Stanley, J. C. (1984). Atherosclerotic extracranial carotid artery aneurysms. Journal of vascular surgery, 1(3), 415-422.

24. Cooper, A. (1836). Account of the first successful operation performed on the common carotid artery for aneurysm in the year 1808 with the postmortem examination in the year 1821. Guys Hosp Rep, 1, 53-59.

25. Schievink, W. I., Piepgras, D. G., McCaffrey, T. V., \& Mokri, B. (1994). Surgical treatment of extracranial internal carotid artery dissecting aneurysms. Neurosurgery, 35(5), 809-816.

26. Zhang, Q., Duan, Z. Q., Xin, S. J., Wang, X. W., \& Dong, Y. T. (1999). Management of Extracranial Carotid Artery Aneurysms: 17 Years» Experience. European journal of vascular and endovascular surgery, 18(2), 162-165.

27. Bergeron, P., Khanoyan, P., Meunier, J. P., Graziani, J. N., \& Gay, J. (2004). Long- Term Results of Endovascular Exclusion of Extracranial Internal Carotid Artery Aneurysms and Dissecting Aneurysm. Journal of interventional cardiology, 17(4), 245-252.

28. Lubicz, B., Gauvrit, J. Y., Leclerc, X., Lejeune, J. P., \& Pruvo, J. P. (2003). Giant aneurysms of the internal carotid artery: endovascular treatment and long-term follow-up. Neuroradiology, 45(9), 650655.

29. Floris Vos, A. W., Linsen, M. A., Diks, J., Rauwerda, J. A., \& Wisselink, W. (2004). Carotid stent mobility with regard to head movements: in vitro analysis. Vascular, 12(6), 369-373. 